\title{
Aberrant DNA Methylation of Imprinted Loci in Male and Female Germ Cells of Infertile Couples
}

\author{
Takahiro Arima ${ }^{1}$, Hiroaki Okae ${ }^{1}$, \\ Hitoshi Hiura ${ }^{1}$, Naoko Miyauchi, ${ }^{1}$, \\ Fumi Sato ${ }^{1}$, Akiko Sato ${ }^{2}$ and Chika Hayashi ${ }^{2}$ \\ ${ }^{1}$ Department of Informative Genetics, \\ Environment and Genome Research Center, \\ Tohoku University Graduate School of Medicine, \\ 2-1 Seiryo-cho, Aoba-ku, Sendai, \\ ${ }^{2}$ Departments of Obstetrics and Gynecology, \\ Tohoku University Graduate School of Medicine, Sendai, \\ Japan
}

\section{Introduction}

Recent studies have identified an increased incidence of the normally rare imprinting disorders, Beckwith-Wiedemann syndrome (BWS; NIM130650) and Angelman syndrome (AS; NIM105830), in ART babyes (DeBaun et al., 2003; Gosden et al., 2003; Maher, 2005). The identification of epigenetic changes at imprinted loci in ART babyes has led to the suggestion that the technique itself may predispose embryos to acquire imprinting errors. Both in vitro fertilization (IVF) and intracytoplasmic sperm injection (ICSI) are associated with the increased risk of imprinting disorders and it is not clear at what point these imprinting errors arise (Bowdin et al., 2007; Doornbos et al., 2007).

Genomic imprinting confers different functions on the two parental genomes during development by silencing one allele of each imprinted gene in a parent-of-origin dependent manner (Ohlsson et al., 1998; Reik and Walter, 1998; Surani, 1998; Tilghman, 1999). Imprinting accounts for the requirement of both maternal and paternal genomes in normal development and plays significant roles in regulating embryonic growth, placental function and neurobehavioral processes (McGrath and Solter, 1984; Surani et al., 1984). Aberrant expression of some imprinted genes has been linked to a number of human diseases, developmental abnormalities and malignant tumors (Paulsen and Ferguson-Smith, 2001). The epigenetic modifications that are imposed during gametogenesis act as primary imprint markers to distinguish the maternal and paternal alleles (Surani, 1998). The most likely candidate for the gametic mark is DNA methylation. Allele-specific DNA methylation has been observed in the vicinity of most imprinted genes. In some instances, the methylation is present on the inactive gene, suggesting a role for DNA methylation in silencing of the gene 
(Figure 1). DNA methylation is both a heritable and reversible epigenetic modification that is stably propagated after DNA replication. In order to transmit this epigenetic mark from one generation to the next, the imprints have to be erased in the primordial germ cells (PGCs) (Hajkova et al., 2002; Lee et al., 2002) and re-established during gametogenesis in a sex-specific manner (Figure 2).

Major epigenetic events take place during female and male germ cell development and the preimplantation stages of embryonic development (Lucifero et al., 2004a). In vitro culture may expose the genome to environmental factors that prevent the proper establishment of the DNA methylation. However, the risks cannot easily be evaluated for ART because patients who receive ART may differ both demographically and genetically from the general people. Usually, patients requesting ART have a low fertility rate, an increased reproductive loss rate and are of advanced age, all of which are associated with various fetal and neonatal abnormalities. These confounding factors make it difficult to evaluate the risk and safety of ART procedures.

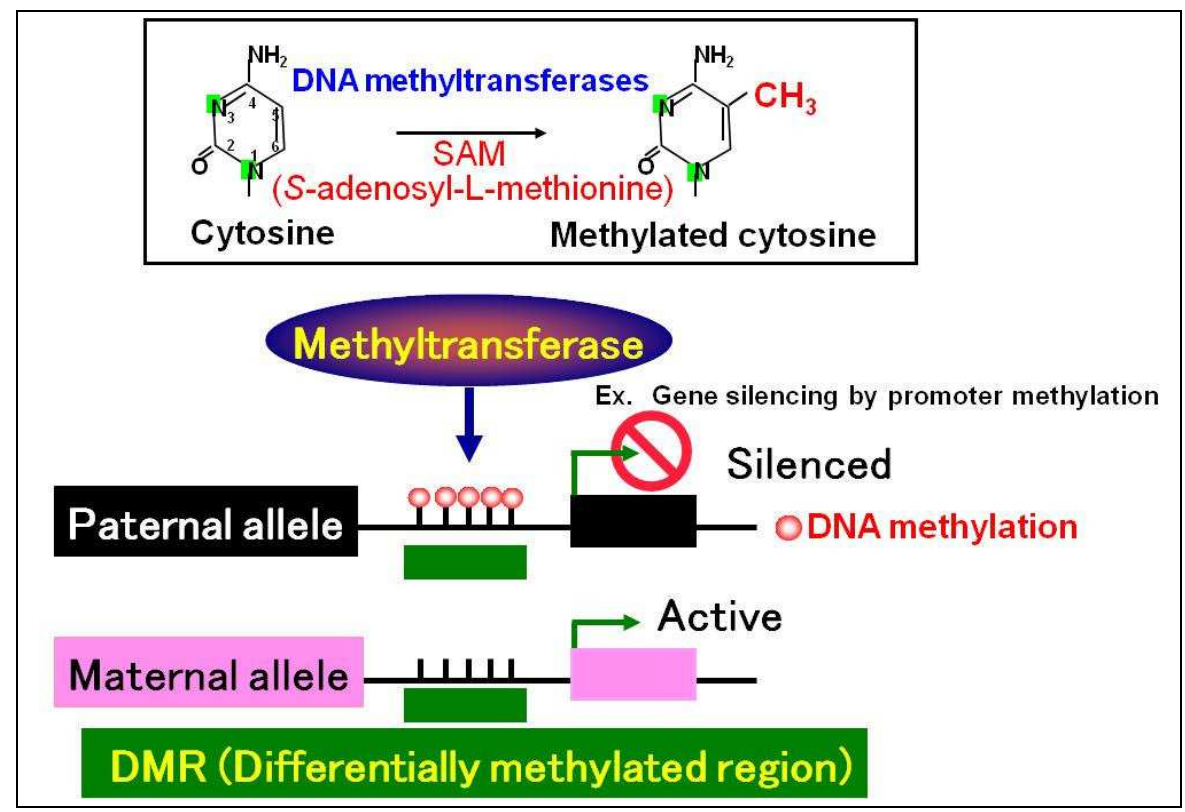

Fig. 1. The regulation of imprinted gene by DNA methylation.

DNA cytosine methylation (methyltransferase) regulates imprinted gene expression. Differentially methylated regions (DMRs) are commonly associated with imprinted genes.

Genomic imprinting is a gamete-specific modification (DNA methylation) that causes differential expression of the two parental alleles. An imprint starts by a gametogenesis process, and it is maintained for stability up to a somatic cell .In addition, it is erased in a primordial germ cell. 


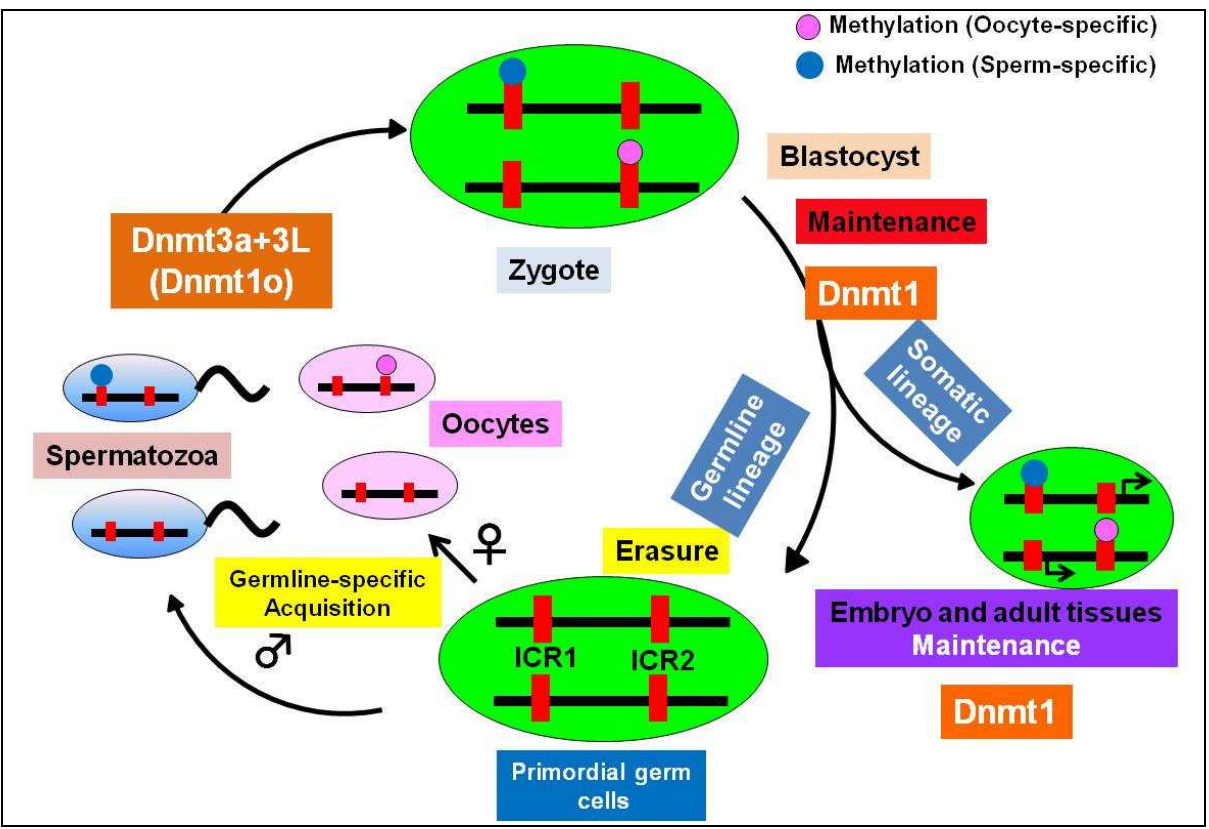

Fig. 2. Imprinted process through the life cycle.

ART involve the isolation, handling and culture of gametes and early embryos, generally after hormone stimulation protocols (superovulation), at a time when the epigenetic marks at imprinted loci are relatively malleable and therefore potentially vulnerable to external influences. Epigenetic marks appear to be at risk during several stages of the ART procedures including the superovulation, various culture mediums, cryopreservation and embryo transfer. Our recent work, and that of others, suggests the possibility that infertile men, particularly those with oligozoospermia, carry imprinting errors in their sperm (Kobayashi et al., 2007; Marques et al., 2004; Marques et al., 2008). Therefore the increase in the incidence of imprinting disorders in individuals born by ART may be due, in some cases, to the use of this sub-optimal sperm.

\subsection{Aberrant of DNA methylation imprint in superovulation oocytes}

Imprinted genes are particularly vulnerable targets for numerous human pathologies since single genetic or epigenetic changes can deregulate their function. Epigenetic mark, DNA methylation is found associated with only one parental allele within discrete locations known as differentially methylated regions (DMRs) (Figure 1)(Surani, 1998). The acquisition of DNA methylation at these key regions occurs primarily in the parental germ line during male and female gametogenesis and is thought to direct the imprinting process (Lucifero et al., 2002; Obata and Kono, 2002).

The acquisition of the imprint methylation marks is significantly different between the two germ lines. In the male germ line, H19, Rasgrf1 and Gtl2 methylation imprints are initiated prenatally during embryonic germ cell development and are complete by the pachytene 
phase of postnatal spermatogenesis in mice (Davis et al., 1999; Davis et al., 2000; Li et al., 2004; Ueda et al., 2000). In contrast, in the female line, the maternal methylations, such as Igf2r, Snrpn, Peg1, Peg3 etc. methylations, are acquired asynchronously in a gene-specific manner, while oocytes are arrested at prophase I and transitioned from primordial to antral follicles during the postnatal growth phase (post-pachytene) (Lucifero et al., 2004b). Nuclear transplantation using postnatal oocytes at various stages of maturation point to this same window of oocyte development as the time when functional imprints are acquired (Bao et al., 2000; Obata and Kono, 2002).

Much debate has recently surrounded the issues of possible epigenetic alterations brought about by human ART (Lucifero et al., 2004a). One of the important issues is artificial induction of ovulation with high doses of gonadotrophins (superovulation). In the ART procedures, a large amount of gonadotrophins are usually used to obtain the mature oocytes. It is uncertain whether exogenous gonadotrophins alter the maturation process of eggs or the physiological environment of the uterus. Studies in animals have suggested that superovulation decreases the viability of embryos (McKiernan and Bavister, 1998; Van der Auwera and D'Hooghe, 2001). We and others showed the occurrence of methylation errors on several imprinted genes in full growing oocytes due to superovulation in humans and mice, which will help to estimate the safety of artificial induction of ovulation (MarketVelker et al., 2010; Sato et al., 2007). Under controlled ovarian stimulations, immature oocytes are collected. These oocytes are usually discarded due to the possibility of abnormal embryonic development or an increased rate of abortion (Smith et al., 2000). However in cases of poor responders and in patients with an unsynchronized cohort of follicles, where the presence of immature oocytes is frequent after stimulation the use of immature oocytes for IVF is important in order to incease the number of embryos obtained in each cycle. In addition, in vitro matured (IVM) oocytes and some devices of maturation might be a significant risk of the imprinting diseases.

\subsection{Aberrant of DNA methylation imprint in oligospermic patients}

In mice, paternally methylation imprints are initiated prenatally during embryonic germ cell development. In humans, limited information is available on the methylation status of imprinted genes during gametogenesis and embryogenesis. During normal spermatogenesis, the erasure of methylation marks of the maternally imprinted gene SNRPN (Manning et al., 2001) and the resetting of the paternally imprinted gene H19 (Kerjean et al., 2000; Marques et al., 2004) have been reported to be completed before germ cells enter meiosis. We and other reported that there was abnormal imprinting in oligospermic patients and in a small number of the normospermic patients (Marques et al., 2004). We examined the DNA methylation status of seven imprinted genes using a combined bisulphite polymerase chain reaction (PCR) restriction analysis and sequencing technique on

We examined the DNA methylation status of several imprinted genes using a combined bisulphite (PCR) restriction analysis and sequencing technique on ejaculated sperm DNA obtained from infertile men. We found abnormal methylation of the paternal imprint in $14.4 \%$ and an abnormal maternal imprint in $20.6 \%$. The majority of these doubly defective samples were in men with moderate or severe oligospermia. These abnormalities were specific to imprinted loci since we found that global DNA methylation was normal in these 
samples (Kobayashi et al., 2007). In our sperm analysis, we found incomplete methylation; normospermia in $15.2 \%$, moderate oligospermia in $37.5 \%$ and severe oligospermia in $80 \%$ (Figure 3). These results reveal that abnormal spermatogenesis (leading to low sperm counts) is associated with a defective imprint methylation.14.4\% and an abnormal maternal imprint in $20.6 \%$. The majority of these doubly defective samples were in men with moderate or severe oligospermia. These abnormalities were specific to imprinted loci since we found that global DNA methylation was normal in these samples (Kobayashi et al., 2007). In our sperm analysis, we found incomplete methylation; normospermia in $15.2 \%$, moderate oligospermia in $37.5 \%$ and severe oligospermia in $80 \%$ (Figure 3). These results reveal that abnormal spermatogenes(leading to low sperm counts) is associated with a defective imprint methylation.

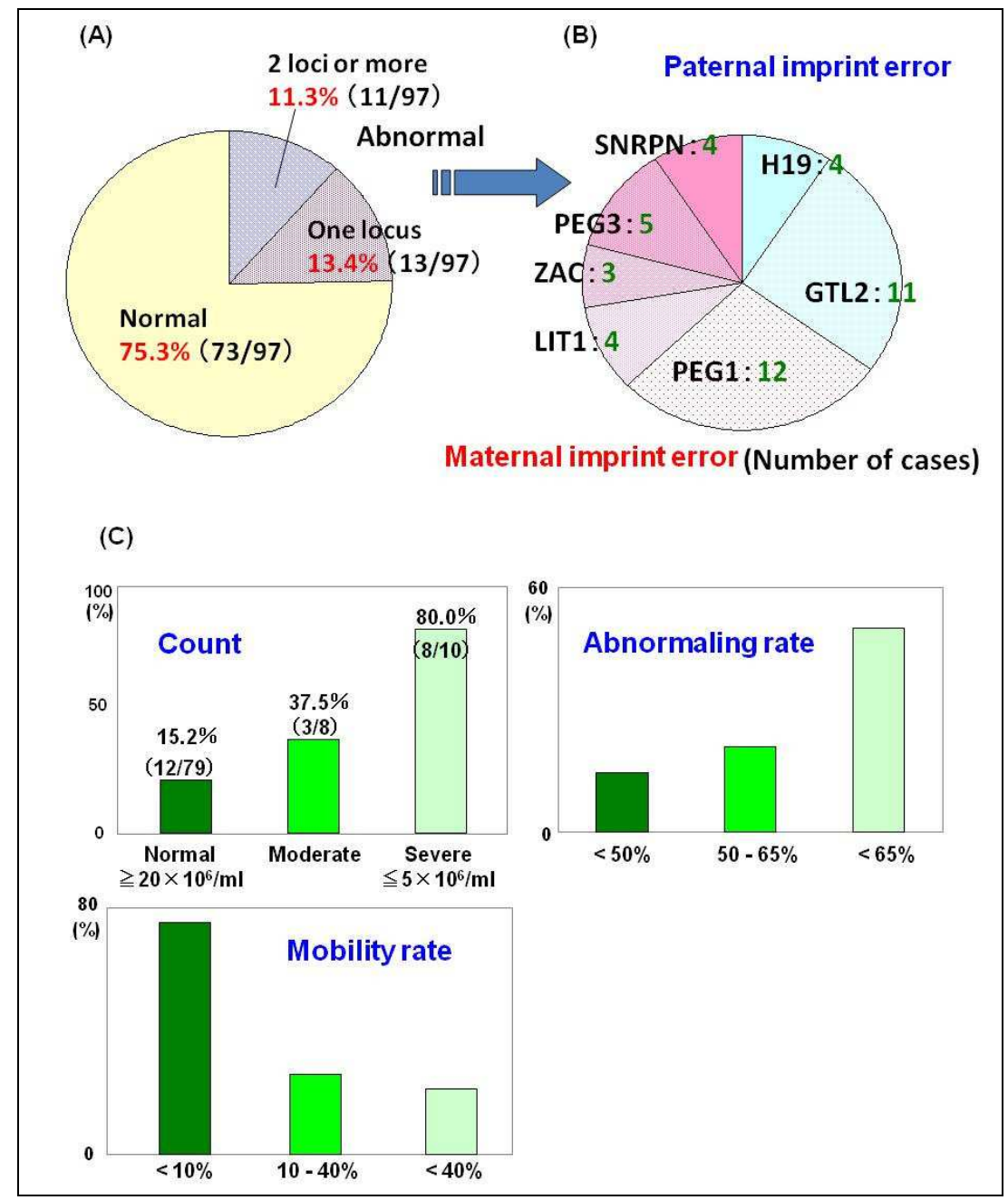

Fig. 3. Aberrant DNA methylation of imprinted loci in sperm from infertile male. 
(A) Frequency of the imprint methylation error (B) Abnormal imprinted loci (C) Abnormal methylation imprint and sperm concentrations. Methylation errors at maternal and paternal imprinted loci that were specific to oligospermic men.

The most frequent methylation error was seen in the PEG1 DMR. In our previous report, we showed that demethylation of PEG1 was present in the growing oocytes from superovulated infertile women (Sato et al., 2007). This PEG1 DMR may be especially vulnerable to errors. In both humans and mice, the PEG1 DMR located in the promoter, the first exon and is unmethylated on the active paternal allele (Kobayashi et al., 1997; Lefebvre et al., 1997). Paternal transmission of a methylated Peg1 gene results in growth-retarded embryos. Abnormal behavior has also been noted in Peg1-deficient females (Lefebvre et al., 1998). Generally, ART babies are characterized by low-weight birth.

Recently, we demonstrated that in a few cases, the methylation errors in the sperm were present in the ART aborted conceptus (Kobayashi et al., 2009).

\subsection{Evidence of imprint defects associated with ART}

Major epigenetic events take place during this time and the process of ART may expose the epigenome to external influences preventing the proper establishment and maintenance of genomic imprints (DeBaun et al., 2003; Maher et al., 2003). Except for superovulation, another issue is related to the culture conditions. Some studies have shown that exposure of mouse embryos to different culture conditions can alter the expression and imprinting of various genes which could result in abnormal development (DeBaun et al., 2003; Gicquel et al., 2003; Maher et al., 2003). The third issue is the potential effect of embryo cryopreservation (Emiliani et al., 2000; Honda et al., 2001). The timing of embryo transfer may also present issues. Some studies on monochorionic dizygotic twins and conjoined twins with BWS resulting from transfer of embryos at the blastocyst stage revealed demethylation of LIT1 (KCNQ1OT1) (Miura and Niikawa, 2005; Shimizu et al., 2004), suggesting that this demethylation occurs at a critical stage of pre-implantation development. Furthermore, there may be other serious issues causing yet unknown risks of ART.

We previously reported cases of a mosaic methylation pattern in ART-babies (Kobayashi et al., 2007). Nutrients, including methyl-substrates such as vitamins B6 and folic acid, influence DNA methylation and histone modification at gene promoters. Imprinting errors in sperm at the paternally-methylated DMRs may be reversed using a similar approach. This approach has already been applied to treat autism (Chen et al., 2003).

\subsection{Automated high-throughput procedure for the detection of alterations in DNA methylation}

Southern blotting was the original technique used routinely to analyse DNA methylation (J.Sambrook and D.W.Russell, 2001). This technique requires a relatively large quantity of DNA $(5-10 \mu \mathrm{g})$ that is usually digested with two restriction enzymes, one of which is methylation sensitive. The DNA is fractionated on an agarose gel, transferred a positively charged nylon membrane, hybridized with a radioisotope labeled probe, washed and exposed to autoradiography. This method has largely been superceded by methods involving The methylation status of a specific sequence can then be measured by combined bisulphite PCR restriction analysis (COBRA) or by the sequencing of the PCR product. The 
sodium bisulphite treatment of genomic DNA converts unmethylated cytosine to uracil leaving the methylated cytosines unconverted. The combination of COBRA and the sequencing method provides accuracy and sensitivity but nonetheless, there are still limitations with this method particularly the expertise required to obtain accurate results, the time taken to achieve a result and the relative cost, rendering it unsuitable for clinical diagnosis. Recently, we developed a new method of DNA methylation analysis, PCRLuminex (Sato et al., 2011). This method combines PCR and sequence-specific oligonucleotide probe (SSOP) protocols with the Luminex 100 xMAP flow cytometry duallaser system to quantitate fluorescently labeled oligonucleotides attached to color-coded microbeads (Figure 4).

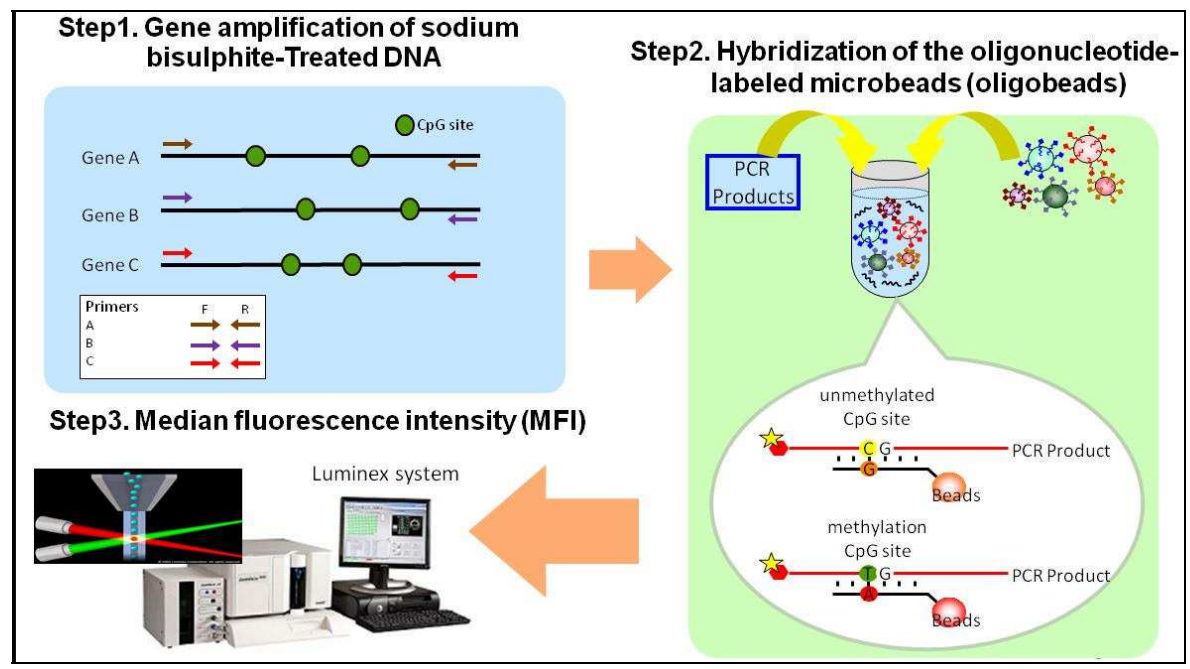

Fig. 4. BPL methylation assay.

Bisulphite PCR-Luminex (BPL) method involved PCR amplification of bisulphite-DNA, hybridization, a streptavidin-phycoerythrin (SA-PE) reaction and identification of the fluorescent microbeads by determining the preset ratio of internalized dyes to distinguish between cytosine and uracil (methylation and non-methylation). This is one of new highthroughput, high-resolution DNA methylation analysis methods.

The PCR-Luminex method can identify one base substitution by specific hybridization and therefore could potentially be applied to the identification of DNA methylation using the bisulphite conversion technique to essentially generate the two different bases, cytosine and uracil (methylation and non-methylation), called BPL. We applied these techniques to examine the methylation imprints of 8 DMRs (paternally methylated DMRs: ZDBF2, H19 and GTL2, maternally methylated DMRs: PEG1, ZAC, SNRPN, PEG3 and LIT1) in the sperm DNA to assess the quality of these samples with respect to imprint status (Sato et al., 2011). BPL In the mean future, new methylation analyses will prove to be a simple, accurate and rapid approach and therefore suitable for clinical application. 


\section{Conclusion}

As a result of our studies and the work of others in this area, we recommend that imprint methylation analyses be added to the routine sperm examination (counting, mobility, abnormality analyses) to identify pre-existing imprint mutations. It may be possible, in the future, to reverse aberrant DNA methylation and the present analysis will provide useful information in that regard. Altered expression and methylation of imprinted genes is a frequent event in adult cancers (Feinberg et al., 2006). In addition to determining the frequency of classic imprinting disorders, it will be important to determine cancer occurrence in ART offspring. A retrospective examination of imprinted loci and the constitution of children born after each ART method will reveal the safest and most ethical approach to use. We believe these studies will be valuable for the development of standard ART. In our opinion, before translating new techniques into practice, more research, particularly in animals, is desirable. In addition, better ART child follow-up and a fresh approach to regulation are also needed.

\section{Acknowledgment}

We would like to thank Mis. Yukiko Abe RA, Mr. Takuya Koshizaka PhD and all the members of our laboratory for their technical assistance.

\section{References}

Bao, S., Obata, Y., Carroll, J., Domeki, I. and Kono, T. (2000). Epigenetic modifications necessary for normal development are established during oocyte growth in mice. Biol Reprod 62, 616-621.

Bowdin, S., Allen, C., Kirby, G., Brueton, L., Afnan, M., Barratt, C., Kirkman-Brown, J., Harrison, R., Maher, E. R. and Reardon, W. (2007). A survey of assisted reproductive technology births and imprinting disorders. Hum Reprod 22, 3237-3240.

Chen, W. G., Chang, Q., Lin, Y., Meissner, A., West, A. E., Griffith, E. C., Jaenisch, R. and Greenberg, M. E. (2003). Derepression of BDNF transcription involves calciumdependent phosphorylation of MeCP2. Science 302, 885-889.

Davis, T. L., Trasler, J. M., Moss, S. B., Yang, G. J. and Bartolomei, M. S. (1999). Acquisition of the H19 methylation imprint occurs differentially on the parental alleles during spermatogenesis. Genomics 58, 18-28.

Davis, T. L., Yang, G. J., McCarrey, J. R. and Bartolomei, M. S. (2000). The H19 methylation imprint is erased and re-established differentially on the parental alleles during male germ cell development. Hum Mol Genet 9, 2885-2894.

DeBaun, M. R., Niemitz, E. L. and Feinberg, A. P. (2003). Association of in vitro fertilization with Beckwith-Wiedemann syndrome and epigenetic alterations of LIT1 and H19. Am J Hum Genet 72, 156-160.

Doornbos, M. E., Maas, S. M., McDonnell, J., Vermeiden, J. P. and Hennekam, R. C. (2007). Infertility, assisted reproduction technologies and imprinting disturbances: a Dutch study. Hum Reprod 22, 2476-2480.

Emiliani, S., Van den Bergh, M., Vannin, A. S., Biramane, J. and Englert, Y. (2000). Comparison of ethylene glycol, 1,2-propanediol and glycerol for cryopreservation of slow-cooled mouse zygotes, 4-cell embryos and blastocysts. Hum Reprod 15, 905-910.

Feinberg, A. P., Ohlsson, R. and Henikoff, S. (2006). The epigenetic progenitor origin of human cancer. Nat Rev Genet 7, 21-33. 
Gicquel, C., Gaston, V., Mandelbaum, J., Siffroi, J. P., Flahault, A. and Le Bouc, Y. (2003). In vitro fertilization may increase the risk of Beckwith-Wiedemann syndrome related to the abnormal imprinting of the KCN1OT gene. Am J Hum Genet 72, 1338-1341.

Gosden, R., Trasler, J., Lucifero, D. and Faddy, M. (2003). Rare congenital disorders, imprinted genes, and assisted reproductive technology. Lancet 361, 1975-1977.

Hajkova, P., Erhardt, S., Lane, N., Haaf, T., El-Maarri, O., Reik, W., Walter, J. and Surani, M. A. (2002). Epigenetic reprogramming in mouse primordial germ cells. Mech Dev 117, 15-23.

Honda, S., Weigel, A., Hjelmeland, L. M. and Handa, J. T. (2001). Induction of telomere shortening and replicative senescence by cryopreservation. Biochem Biophys Res Commun 282, 493-498.

J.Sambrook and D.W.Russell. (2001). Molecular Cloning,third edition: Cold Spring Harbor Laboratory Press.

Kerjean, A., Dupont, J. M., Vasseur, C., Le Tessier, D., Cuisset, L., Paldi, A., Jouannet, P. and Jeanpierre, M. (2000). Establishment of the paternal methylation imprint of the human H19 and MEST/PEG1 genes during spermatogenesis. Hum Mol Genet 9, 2183-2187.

Kobayashi, H., Hiura, H., John, R. M., Sato, A., Otsu, E., Kobayashi, N., Suzuki, R., Suzuki, F., Hayashi, C., Utsunomiya, T. et al. (2009). DNA methylation errors at imprinted loci after assisted conception originate in the parental sperm. Eur J Hum Genet 17, 1582-1591.

Kobayashi, H., Sato, A., Otsu, E., Hiura, H., Tomatsu, C., Utsunomiya, T., Sasaki, H., Yaegashi, N. and Arima, T. (2007). Aberrant DNA methylation of imprinted loci in sperm from oligospermic patients. Hum Mol Genet 16, 2542-2551.

Kobayashi, S., Kohda, T., Miyoshi, N., Kuroiwa, Y., Aisaka, K., Tsutsumi, O., Kaneko-Ishino, T. and Ishino, F. (1997). Human PEG1/MEST, an imprinted gene on chromosome 7. Hum Mol Genet 6, 781-786.

Lee, J., Inoue, K., Ono, R., Ogonuki, N., Kohda, T., Kaneko-Ishino, T., Ogura, A. and Ishino, F. (2002). Erasing genomic imprinting memory in mouse clone embryos produced from day 11.5 primordial germ cells. Development 129, 1807-1817.

Lefebvre, L., Viville, S., Barton, S. C., Ishino, F., Keverne, E. B. and Surani, M. A. (1998). Abnormal maternal behaviour and growth retardation associated with loss of the imprinted gene Mest. Nat Genet 20, 163-169.

Lefebvre, L., Viville, S., Barton, S. C., Ishino, F. and Surani, M. A. (1997). Genomic structure and parent-of-origin-specific methylation of Peg1. Hum Mol Genet 6, 1907-1915.

Li, J. Y., Lees-Murdock, D. J., Xu, G. L. and Walsh, C. P. (2004). Timing of establishment of paternal methylation imprints in the mouse. Genomics 84, 952-960.

Lucifero, D., Chaillet, J. R. and Trasler, J. M. (2004a). Potential significance of genomic imprinting defects for reproduction and assisted reproductive technology. Hum Reprod Update 10, 3-18.

Lucifero, D., Mann, M. R., Bartolomei, M. S. and Trasler, J. M. (2004b). Gene-specific timing and epigenetic memory in oocyte imprinting. Hum Mol Genet 13, 839-849.

Lucifero, D., Mertineit, C., Clarke, H. J., Bestor, T. H. and Trasler, J. M. (2002). Methylation dynamics of imprinted genes in mouse germ cells. Genomics 79, 530-538.

Maher, E. R. (2005). Imprinting and assisted reproductive technology. Hum Mol Genet 14 Spec No 1, R133-138.

Maher, E. R., Brueton, L. A., Bowdin, S. C., Luharia, A., Cooper, W., Cole, T. R., Macdonald, F., Sampson, J. R., Barratt, C. L., Reik, W. et al. (2003). Beckwith-Wiedemann syndrome and assisted reproduction technology (ART). J Med Genet 40, 62-64. 
Manning, M., Lissens, W., Weidner, W. and Liebaers, I. (2001). DNA methylation analysis in immature testicular sperm cells at different developmental stages. Urol Int 67, 151-155.

Market-Velker, B. A., Zhang, L., Magri, L. S., Bonvissuto, A. C. and Mann, M. R. (2010). Dual effects of superovulation: loss of maternal and paternal imprinted methylation in a dose-dependent manner. Hum Mol Genet 19, 36-51.

Marques, C. J., Carvalho, F., Sousa, M. and Barros, A. (2004). Genomic imprinting in disruptive spermatogenesis. Lancet 363, 1700-1702.

Marques, C. J., Costa, P., Vaz, B., Carvalho, F., Fernandes, S., Barros, A. and Sousa, M. (2008). Abnormal methylation of imprinted genes in human sperm is associated with oligozoospermia. Mol Hum Reprod 14, 67-74.

McGrath, J. and Solter, D. (1984). Completion of mouse embryogenesis requires both the maternal and paternal genomes. Cell 37, 179-183.

McKiernan, S. H. and Bavister, B. D. (1998). Gonadotrophin stimulation of donor females decreases post-implantation viability of cultured one-cell hamster embryos. Hum Reprod 13, 724-729.

Miura, K. and Niikawa, N. (2005). Do monochorionic dizygotic twins increase after pregnancy by assisted reproductive technology? J Hum Genet 50, 1-6.

Obata, Y. and Kono, T. (2002). Maternal primary imprinting is established at a specific time for each gene throughout oocyte growth. J Biol Chem 277, 5285-5289.

Ohlsson, R., Tycko, B. and Sapienza, C. (1998). Monoallelic expression: 'there can only be one'. Trends Genet 14, 435-438.

Paulsen, M. and Ferguson-Smith, A. C. (2001). DNA methylation in genomic imprinting, development, and disease. J Pathol 195, 97-110.

Reik, W. and Walter, J. (1998). Imprinting mechanisms in mammals. Curr Opin Genet Dev 8, 154-164.

Sato, A., Hiura, H., Okae, H., Miyauchi, N., Abe, Y., Utsunomiya, T., Yaegashi, N. and Arima, T. (2011). Assessing loss of imprint methylation in sperm from subfertile men using novel methylation polymerase chain reaction Luminex analysis. Fertil Steril 95, 129-134, 134 e1-4.

Sato, A., Otsu, E., Negishi, H., Utsunomiya, T. and Arima, T. (2007). Aberrant DNA methylation of imprinted loci in superovulated oocytes. Hum Reprod 22, 26-35.

Shimizu, Y., Fukuda, J., Sato, W., Kumagai, J., Hirano, H. and Tanaka, T. (2004). Firsttrimester diagnosis of conjoined twins after in-vitro fertilization-embryo transfer (IVF-ET) at blastocyst stage. Ultrasound Obstet Gynecol 24, 208-209.

Smith, S. D., Mikkelsen, A. and Lindenberg, S. (2000). Development of human oocytes matured in vitro for 28 or 36 hours. Fertil Steril 73, 541-544.

Surani, M. A. (1998). Imprinting and the initiation of gene silencing in the germ line. Cell 93, 309-312.

Surani, M. A., Barton, S. C. and Norris, M. L. (1984). Development of reconstituted mouse eggs suggests imprinting of the genome during gametogenesis. Nature 308, 548-550.

Tilghman, S. M. (1999). The sins of the fathers and mothers: genomic imprinting in mammalian development. Cell 96, 185-193.

Ueda, T., Abe, K., Miura, A., Yuzuriha, M., Zubair, M., Noguchi, M., Niwa, K., Kawase, Y., Kono, T., Matsuda, Y. et al. (2000). The paternal methylation imprint of the mouse H19 locus is acquired in the gonocyte stage during foetal testis development. Genes Cells 5, 649-659.

Van der Auwera, I. and D'Hooghe, T. (2001). Superovulation of female mice delays embryonic and fetal development. Hum Reprod 16, 1237-1243. 


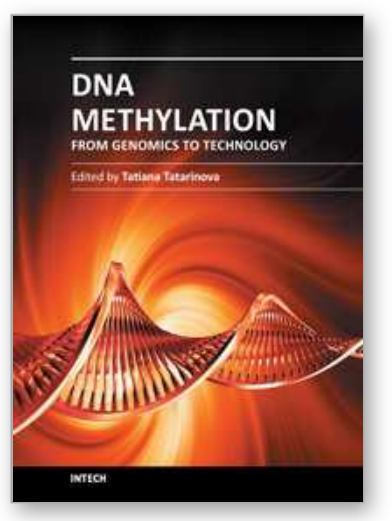

\author{
DNA Methylation - From Genomics to Technology \\ Edited by Dr. Tatiana Tatarinova
}

ISBN 978-953-51-0320-2

Hard cover, 400 pages

Publisher InTech

Published online 16, March, 2012

Published in print edition March, 2012

Epigenetics is one of the most exciting and rapidly developing areas of modern genetics with applications in many disciplines from medicine to agriculture. The most common form of epigenetic modification is DNA methylation, which plays a key role in fundamental developmental processes such as embryogenesis and also in the response of organisms to a wide range of environmental stimuli. Indeed, epigenetics is increasing regarded as one of the major mechanisms used by animals and plants to modulate their genome and its expression to adapt to a wide range of environmental factors. This book brings together a group of experts at the cutting edge of research into DNA methylation and highlights recent advances in methodology and knowledge of underlying mechanisms of this most important of genetic processes. The reader will gain an understanding of the impact, significance and recent advances within the field of epigenetics with a focus on DNA methylation.

\title{
How to reference
}

In order to correctly reference this scholarly work, feel free to copy and paste the following:

Takahiro Arima, Hiroaki Okae, Hitoshi Hiura, Naoko Miyauchi, Fumi Sato, Akiko Sato and Chika Hayashi (2012). Aberrant DNA Methylation of Imprinted Loci in Male and Female Germ Cells of Infertile Couples, DNA Methylation - From Genomics to Technology, Dr. Tatiana Tatarinova (Ed.), ISBN: 978-953-51-0320-2, InTech, Available from: http://www.intechopen.com/books/dna-methylation-from-genomics-to-technology/aberrant-dnamethylation-of-imprinted-loci-in-male-and-female-germ-cells-of-infertile-couples

\section{INTECH}

open science | open minds

\section{InTech Europe}

University Campus STeP Ri

Slavka Krautzeka 83/A

51000 Rijeka, Croatia

Phone: +385 (51) 770447

Fax: +385 (51) 686166

www.intechopen.com

\section{InTech China}

Unit 405, Office Block, Hotel Equatorial Shanghai

No.65, Yan An Road (West), Shanghai, 200040, China

中国上海市延安西路65号上海国际贵都大饭店办公楼 405 单元

Phone: +86-21-62489820

Fax: $+86-21-62489821$ 
(C) 2012 The Author(s). Licensee IntechOpen. This is an open access article distributed under the terms of the Creative Commons Attribution 3.0 License, which permits unrestricted use, distribution, and reproduction in any medium, provided the original work is properly cited. 